\title{
Lipid nanoparticles as delivery vehicles for the Parietaria judaica major allergen Par j 2
}

This article was published in the following Dove Press journal:

International Journal of Nanomedicine

I8 November 2011

Number of times this article has been viewed

\author{
Maria Luisa Bondi ${ }^{1, *}$ \\ Giovanna Montana 2 ,* \\ Emanuela Fabiola Craparo ${ }^{3}$ \\ Roberto Di Gesù ${ }^{3}$ \\ Gaetano Giammona ${ }^{3}$ \\ Angela Bonura ${ }^{2}$ \\ Paolo Colombo 2 \\ 'Istituto per lo Studio dei Materiali \\ Nanostrutturati, ${ }^{2}$ Istituto di \\ Biomedicina ed Immunologia \\ Molecolare, Consiglio Nazionale \\ delle Ricerche, ${ }^{3}$ Laboratory of \\ Biocompatible Polymers, Dipartimento \\ di Scienze e Tecnologie Molecolari e \\ Biomolecolari Stembio, Università di \\ Palermo, Palermo, Italy \\ *These authors contributed equally to \\ this work
}

Correspondence: Maria Luisa Bondi Istituto per lo Studio dei Materiali Nanostrutturati, Consiglio Nazionale delle Ricerche, via Ugo La Malfa, I53, 90146 Palermo, Italy

Tel +39 9l 6809367

Fax +39916809399

Email marialuisa.bondi@ismn.cnr.it

\begin{abstract}
Parietaria pollen is one of the major causes of allergic reaction in southern Europe, affecting about $30 \%$ of all allergic patients in this area. Specific immunotherapy is the only treatment able to modify the natural outcome of the disease by restoring a normal immunity against allergens. The preparation of allergen-solid lipid nanoparticles as delivery vehicles for therapeutic proteins, P. judaica major allergen Par j 2, was investigated. The Par $\mathrm{j} 2$ allergen was expressed in a large amount in Escherichia coli and purified to homogeneity. Its immunological properties were studied by western blotting and enzyme-linked immunosorbent assay inhibition. Solid lipid nanoparticles were obtained by water-in-oil-in-water multiple emulsion method and characterized in terms of mean size and surface charge. These systems (approximately $250 \mathrm{~nm}$ diameter and negative surface charge) incorporated recombinant Par j 2 with $40 \%$ or greater efficiency. Moreover, the endotoxin level and anaphylactic activity of the empty solid lipid nanoparticles and recombinant Par j 2-loaded solid lipid nanoparticles were evaluated by looking at the overexpression of CD203c marker on human basophils. These results demonstrate that recombinant Par j 2-nanoparticles could be proposed as safe compositions for the development of new therapeutic dosage forms to cure allergic reactions.
\end{abstract}

Keywords: solid lipid nanoparticles, Parietaria judaica (Par j), drug delivery, recombinant allergens, specific immunotherapy, allergic rhinitis

\section{Introduction}

Allergy is an immunoglobulin E ( $\operatorname{IgE}$ )-mediated hypersensitivity reaction affecting the respiratory tract (rhinitis, rhinoconjunctivitis, urticaria, and asthma). It is a global health problem affecting more than $25 \%$ of the population living in industrialized countries ${ }^{1}$ with significant worldwide increases in the prevalence of asthma and allergic rhinitis since $1960 .^{2}$ This pathological status is characterized by the presence of $\operatorname{IgE}$ antibodies towards molecules from different sources (eg, pollen, animal dander, dust) capable of triggering the release of inflammatory substances from effector cells of the immune system (mast cells, basophils). Parietaria is a genus of dicotyledonous weeds belonging to the Urticaceae family which is composed of several cross-reactive allergenic species representing a common cause of pollinosis in the Mediterranean area. $^{3-5}$ Using DNA recombinant technology, the major allergens of $P$. judaica (Par j 1 and Par j 2) were isolated and characterized in the authors' labs. ${ }^{3}$ So far, the Par j 2 allergen has been a well established marker for the diagnosis of Parietaria pollinosis and, for this reason, it represents the primary target to tackle for the development of new therapeutic strategies. ${ }^{6}$ 
Specific immunotherapy is the only treatment capable of modifying the natural immune response in order to ameliorate symptoms, thereby reducing the consumption of drugs and arresting the natural progression of the disease. ${ }^{7}$ For these reasons, the development of new pharmaceutical products that can improve the safety and efficacy of novel forms of vaccine is of utmost importance in the clinic.

Recently, recombinant allergens have also been used in clinical trials, which shows that these products may represent new formulations of tailored immunotherapy vaccines. ${ }^{8}$ In addition, different routes for the administration of vaccines have recently been exploited. ${ }^{9}$

Solid lipid nanoparticulate systems such as solid lipid nanoparticles (SLN) have been sought as vehicles for therapeutic peptides, proteins, and antigens. ${ }^{10,11}$ Taking into consideration that peptide or protein antigens are ineffective for mucosal immunization due to proteolytic degradation at mucosal sites, encapsulation into particulate carriers is a potential strategy to improve vaccine efficacy after administration by parenteral routes or upon uptake at mucosal sites. ${ }^{11}$ Lipid-based particles have already been successfully obtained for the intranasal immunization against hepatitis B, and a recent report describes oral immunization in mice with SLN containing a Japanese encephalitis antigen. ${ }^{12,13}$ Despite the important efforts dedicated to the design of peptide delivery systems, the administration of these sensitive molecules remains a challenge.

SLN are excellent drug carriers thanks to many advantages associated with their use. In fact, they are quite easy to produce without necessarily using organic solvents, and large-scale production is possible with qualified production lines. ${ }^{14-16}$ They exhibit good stability during long-term storage and are amenable to both lyophilization and steam sterilization. ${ }^{11}$ Moreover, SLN consist of physiologically well-tolerated ingredients often already approved for pharmaceutical applications in humans and are generally recognized as safe. ${ }^{15}$ Under optimized conditions, they can be produced to incorporate therapeutic peptides and proteins. In fact, formulation in SLN confers improved protein stability and avoids proteolytic degradation, granting sustained release of the incorporated molecules. Important peptides have been incorporated into SLN and several therapeutic applications may be foreseen, such as immunization with protein antigens. ${ }^{11}$

This study focuses on the production, purity estimation,

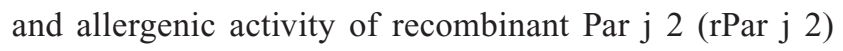
allergen. The preparation and chemical-physical characterization of empty and rPar j 2-loaded SLN are described in detail and the endogenous content in lipopolysaccharides (LPS) into empty SLN and rPar j 2-loaded SLN is analyzed. The study culminates in the evaluation of the anaphylactic activities of rPar j 2-loaded SLN and rPar j 2 allergen.

\section{Materials and methods Induction and purification of $r$ Par $j 2$ allergen}

The recombinant allergen was expressed as a histidinetagged protein (pQE-30 Vector; QIAGEN Ltd, Crawley, United Kingdom) in the M15 strain (Escherichia coli Host Strain M15[pREP4]; QIAGEN). The recombinant clones were grown overnight at $37^{\circ} \mathrm{C}$ in $2 \mathrm{YT}$ broth (bacto tryptone $16 \mathrm{~g} / \mathrm{L}$, bacto yeast $10 \mathrm{~g} / \mathrm{L}$, sodium chloride $5 \mathrm{~g} / \mathrm{L}, \mathrm{pH} 7.0$ ). A 1:40 dilution was taken for 2 hours at $37^{\circ} \mathrm{C}$ and then induced with $1 \mathrm{mM}$ isopropylthio- $\beta$-galactoside for 4 hours at $37^{\circ} \mathrm{C}$. Cells were harvested by centrifugation (5000 rpm for 15 minutes at $4^{\circ} \mathrm{C}$ ) and disrupted by using a sonicator device (Bandelin Sonoplus Ultrasonic homogenizer HD 2200, Berlin, Germany) in a buffer containing $10 \mathrm{mM}$ of sodium phosphate at $\mathrm{pH}$ 7.4. Cell debris was removed by centrifugation at $10,000 \mathrm{rpm}$ for 30 minutes at $4^{\circ} \mathrm{C}$. Supernatant was filtered through a disposable sterile $0.8 \mu \mathrm{m}$ syringe disc-type filter (Corning Life Sciences, Lowell, MA) to disrupt genomic DNA and loaded on an ion exchange CM Sephadex ${ }^{\circledR}$ C-25 column (GE Healthcare, Amersham, United Kingdom). The recombinant proteins were eluted using a discontinuous sodium chloride gradient ( $0-2 \mathrm{M}$ sodium chloride, $10 \mathrm{mM}$ sodium phosphate at $\mathrm{pH}$ 7.4). The outcoming fractions were analyzed by $16 \%$ sodium dodecyl sulfate polyacrylamide gel electrophoresis (SDS-PAGE) and blotted on nitrocellulose membrane (Amersham ${ }^{\mathrm{TM}}$ ECL $^{\mathrm{TM}}$ Western Blotting System; GE Healthcare, Hertfordshire, UK). Membranes were incubated with an antihistidine specific probe (INDIA ${ }^{\mathrm{TM}}$ HisProbe HRP, EuroClone SpA, Milan, Italy) in order to detect fractions containing rPar j 2 protein. Fractions containing the allergens were collected and loaded on a HisTrap ${ }^{\mathrm{TM}} \mathrm{FF}$ Column (GE Healthcare, Hertfordshire, UK) equilibrated in starting buffer (10 mM sodium phosphate at $\mathrm{pH} 7.4,1 \mathrm{M}$ sodium chloride, $10 \mathrm{mM}$ imidazole). The column was washed in wash buffer (10-50 $\mathrm{mM}$ imidazole in starting buffer) and the histidine-tagged proteins were eluted by using a discontinuous imidazole gradient (50-500 $\mathrm{mM}$ imidazole in starting buffer). Then, fractions were analyzed on a $16 \%$ SDS-PAGE gel, and aliquots containing the recombinant allergens were pooled, diluted 1:25 in starting buffer, and reloaded on a second HisTrap column and eluted using an 
elution buffer (10 mM sodium phosphate at $\mathrm{pH} 7.4,1 \mathrm{M}$ sodium chloride, $500 \mathrm{mM}$ imidazole). Eluted fractions containing rPar j 2 were desalted using a Sephadex ${ }^{\circledR}$ G-25 Superfine column (GE Healthcare, Hertfordshire, UK) equilibrated in $1 \times$ phosphate buffered saline (PBS). Its concentration was determined by Coomassie Brilliant Blue staining and densitometric analysis (Quantity One ${ }^{\circledR}$ 1-D Analysis Software; BioRad Laboratories, Hercules, CA). Finally, rPar j 2 was further purified by using DetoxiGel Endotoxin Removing Gel (Thermo Fisher Scientific, Rockford, IL) following manufacturer's instructions.

\section{Preparation of empty and rPar j 2-loaded SLN}

Empty and rPar j 2-loaded SLN were prepared by double emulsion-solvent evaporation method (water-in-oil-in-water). Briefly, to prepare the lipid phase, cutin (mixture of glycerol monostearate and diglyceride, $100 \mathrm{mg}$; Cognis, Dusseldorf, Germany) was heated at $5^{\circ} \mathrm{C}-10^{\circ} \mathrm{C}$ above its melting point and an organic phase of dichloromethane solution $(1.5 \mathrm{~mL}$; Sigma-Aldrich Corporation, St Louis, MO) containing Epikuron $^{\text {TM }} 200$ (20 mg; Cargill Deutschland GmbH, Krefeld, Germany) was added. Then, an aqueous phase $(100 \mu \mathrm{L}$ Milli-Q ${ }^{\mathrm{TM}}$ water; EMD Millipore, Billerica, MA) or an aqueous dispersion of $\operatorname{rPar} \mathrm{j} 2(100 \mu \mathrm{L}, 100 \mathrm{ng} / \mu \mathrm{L})$ was added to this organic solution under stirring by Ultra-Turrax ${ }^{\circledR} \mathrm{T} 125$ (IKA Labortechnik, Staufen, Germany) at 13,500 rpm in order to obtain empty or rPar j 2-loaded SLN. After that, a first aqueous solution of Tween $80^{\circledR}(3 \mathrm{~mL}$ at $2 \%$; Sigma-Aldrich, Milan, Italy) and a second one ( $6 \mathrm{~mL}$ at $1 \%$ ) were added and stirred again by Ultra-Turrax at 13,500 rpm. The organic solvent was evaporated under vacuum for 30 minutes and the obtained aqueous dispersion of nanoparticles was centrifuged at 45,000 rpm (Beckman Optima XL-90 Ultracentrifuge; Beckman Coulter, Inc, Brea, CA) for 1 hour at $4^{\circ} \mathrm{C}$. Finally, the samples were freeze-dried (Modulyo Freeze Dryer; Edwards Ltd, Crawley, United Kingdom) and stored for successive characterization. In order to obtain sterile samples, Milli-Q water was substituted with sterile water (clinical grade pyrogen-free water; EuroClone); glass and metallic tools were sterilized in oven at $180^{\circ} \mathrm{C}$ for 48 hours.

Preliminary studies were performed by high-performance liquid chromatography (HPLC) analysis (Jupiter ${ }^{\circledR} 5 \mu \mathrm{m}$ C5 $250 \times 4.6 \mathrm{~mm}$ internal diameter; Phenomenex, Inc, Torrance, $\mathrm{CA}$ ) to ensure rPar $\mathrm{j} 2$ stability above the lipid melting point so nanoparticles could be obtained. No degradation process occurred on the protein at tested conditions (data not shown).

\section{SLN characterization: mean size and zeta potential}

The mean diameter and width of distribution (polydispersity index, PDI) of each sample were determined by photon correlation spectroscopy (Zetasizer Nano ZS; Malvern Instruments Ltd, Malvern, United Kingdom) that utilized noninvasive back-scattering technique. Each dried sample was appropriately suspended with filtered $(0.45 \mu \mathrm{m})$ bidistilled water, isotonic aqueous solution (sodium chloride $0.9 \%$ weight-in-weight), or PBS (at $\mathrm{pH}$ 7.4), and the reading was carried at a $173^{\circ}$ angle in respect to the incident beam. Each reported value was the average of three measurements. The deconvolution of the measured correlation curve to an intensity size distribution was accomplished by using a nonnegative least-squares algorithm.

Zeta potential values were measured according to the principles of laser Doppler velocimetry and phase analysis light scattering (M3-PALS technique). In support of that, a Zetasizer Nano ZS (Malvern) was used. Freeze-dried SLN samples were dispersed in the same media utilized for size measurements. Each sample was analyzed in triplicate.

\section{rPar j 2 encapsulation efficiency}

The encapsulation efficiency was determined directly and indirectly. In order to determine $\mathrm{rPar} \mathrm{j} 2$ encapsulation efficiency directly on rPar j 2-loaded SLN, an HPLC method was developed. HPLC analysis was performed by using a C5 column (Phenomenex); the mobile phase was a mixture of acetonitrile/trifluoroacetic acid $(0.1 \%$ volume to volume $[\mathrm{v} / \mathrm{v}])$ and water/trifluoroacetic acid $(0.1 \% \mathrm{v} / \mathrm{v})$ with a flow rate of $1 \mathrm{~mL} /$ minute, reading at $\lambda 280 \mathrm{~nm}$, and utilizing a gradient method with an increase of organic phase from $10 \%$ to $60 \%$ in 1 -hour period. For this purpose, $10 \mathrm{mg}$ of rPar j 2-loaded SLN were dissolved in $1 \mathrm{~mL}$ of dichloromethane and then $1 \mathrm{~mL}$ of water was added in order to extract the allergen. The latter was repeated until exhaustive extraction. Results were expressed as weight percent ratio between loaded rPar j 2 and total amount of rPar j 2 used to prepare the nanoparticles. For indirect analysis, the amount of protein entrapped into SLN was calculated by the difference between total amount of rPar j 2 used to prepare the nanoparticles and amount of protein remaining in the aqueous phase (supernatant) after SLN separation. Protein concentration in the supernatant was determined by HPLC analysis as reported above. 


\section{Storage stability}

Both lyophilized empty and rPar j 2-loaded SLN were stored at $4^{\circ} \mathrm{C}$ for 4 months and 10 months in the dark. After this period of storage, samples were dispersed in bidistilled water and characterized in terms of mean size, PDI, zeta potential, and drug stability.

\section{Western blotting}

IgE-binding activity of the purified recombinant allergen was studied by western blotting by using ten sera from clinically characterized Parietaria allergic patients. In particular, rPar $\mathrm{j} 2$ was fractionated by $16 \%$ SDS-PAGE and blotted to nitrocellulose membranes (Hybond ${ }^{\mathrm{TM}} \mathrm{ECL}^{\mathrm{TM}}$ [GE Healthcare]). Sera were diluted 1:5 in buffer A (1× PBS, $0.1 \%$ Tween $20^{\circledR}$ [Sigma-Aldrich], and $0.25 \%$ bovine serum albumin) and incubated with blotted membranes overnight at room temperature. IgE complexes were detected by using a BioSource ${ }^{\mathrm{TM}}$ goat antihuman IgE-horseradish peroxidase conjugate (Invitrogen, Monza, Italy) and visualized by autoradiography as previously described. ${ }^{22}$

\section{Enzyme-linked immunosorbent assay inhibition}

Microtiter plates (Greiner Bio-One, Frickenhausen, Germany) were coated with the $P$. judaica extract $(20 \mathrm{mg} / \mathrm{mL})$ in carbonate/bicarbonate buffer ( $\mathrm{pH}$ 9.6) overnight at room temperature. Plates were washed with PBS and $0.05 \% \mathrm{v} / \mathrm{v}$ Tween 20. Nonspecific binding sites were blocked with PBS and $1 \%$ weight-in-volume bovine serum albumin for 1 hour at room temperature. Inhibition assay was performed by adding serum samples (diluted 1:5) in PBS, $0.5 \%$ weight-in-volume bovine serum albumin, and $0.05 \% \mathrm{v} / \mathrm{v}$ Tween 20 and preincubated overnight at room temperature with increasing concentrations of the allergen used as inhibitor (P. judaica extract: from 100 to $0.16 \mathrm{mg} / \mathrm{mL}$; rPar j 2: from 5 to $0.04 \mathrm{mg} / \mathrm{mL}$ ) in dilution buffer.

Plates were washed between each incubation step with PBS and $0.05 \% \mathrm{v} / \mathrm{v}$ Tween 20 . Bound antibodies were detected by using a goat antihuman IgE-horse radish peroxidase conjugate (Invitrogen, Milan, Italy) as previously described ${ }^{17}$ The percentage of inhibition of human IgE binding was calculated as follows: $100-\left(\mathrm{OD}_{\mathrm{I}} / \mathrm{OD}_{\mathrm{P}} \times 100\right)$, where $\mathrm{OD}_{\mathrm{I}}$ and $\mathrm{OD}_{\mathrm{P}}$ represent the absorbance after preincubation with treated serum and untreated serum, respectively.

\section{Endotoxin content}

LPS contamination of rPar $\mathrm{j} 2$ allergen and SLN particles was evaluated using the multitest limulus amebocyte lysate
QCL-1000 ${ }^{\circledR}$ (Cambrex Corporation, East Rutherford, NJ) (endogenous endotoxin sensitivity $\leq 0.03 \mathrm{EU} / \mathrm{mL}$ ). In order to determine the endotoxin concentration of samples, serial twofold dilutions of each sample were tested until an endpoint was reached. Lysate sensitivity was calculated by determining the geometric mean of the endpoint, each endpoint value being converted to $\log 10$. The individual $\log 10$ values were averaged and lysate sensitivity was taken as the antilog 10 of this average $\log$ value.

\section{CD203c basophil activation assay}

Heparinized peripheral blood was obtained from nonallergic subjects $(n=2)$. Aqueous suspensions of empty SLN (10 ng/mL and $100 \mathrm{ng} / \mathrm{mL}$ in $1 \times$ PBS $)$ and dilutions of the free allergen and rPar j 2-loaded SLN (10 ng/mL and $100 \mathrm{ng} / \mathrm{mL}$ in $1 \times$ PBS) were incubated with $100 \mu \mathrm{L}$ of blood for 15 minutes at $37^{\circ} \mathrm{C}$; $1 \times$ PBS was used as a negative control. AntiIgE antibodies were used as positive control $(1 \mu \mathrm{g} / \mathrm{mL})$. After incubation, cells were resuspended in 100 of $\mu \mathrm{LACS}^{\mathrm{TM}}$ buffer (Becton, Dickinson and Company, Franklin Lakes, NJ) and incubated with $20 \mu \mathrm{L} /$ test of phycoerythrin-labeled antiCD203c mAb 97 A6 (Immunotech, Marseille, France) for 20 minutes at $4{ }^{\circ} \mathrm{C}$ in the dark. Samples were subjected to erythrocyte lyses, washed twice in ice cold FACS buffer, and analyzed by means of flow cytometry on FACSCalibur ${ }^{\mathrm{TM}}$ flow cytometer (Becton Dickinson). Basophils were detected on the basis of side-scatter characteristics and expression of CD203c. For each sample, 100,000-200,000 cells were analyzed. Analysis gates were set on lymphocytes by forward and side-scatter profile and on $\mathrm{CD}^{+}$cells. Results were analyzed by using WinMDI 2.8 software (Scripps Research Institute, Jupiter, FL).

\section{Results and discussion}

This work aimed to set up and standardize the preparation of a recombinant allergenic protein encapsulated within SLN for the realization of new forms of stable and safe vaccines for the treatment of allergic disorders. Moreover, a protocol for the expression and purification at homogeneity of P. judaica major allergen Par $\mathrm{j} 2$ in E. coli was standardized. Furthermore, the immunological activity of $\mathrm{rPar} \mathrm{j} 2$, empty SLN, and rPar j 2-loaded SLN was evaluated.

\section{Purification and lgE-binding activity of the obtained $r$ Par $j 2$ allergen}

The rPar j 2 allergen was purified at homogeneity using independent chromatography techniques. Yield of the 


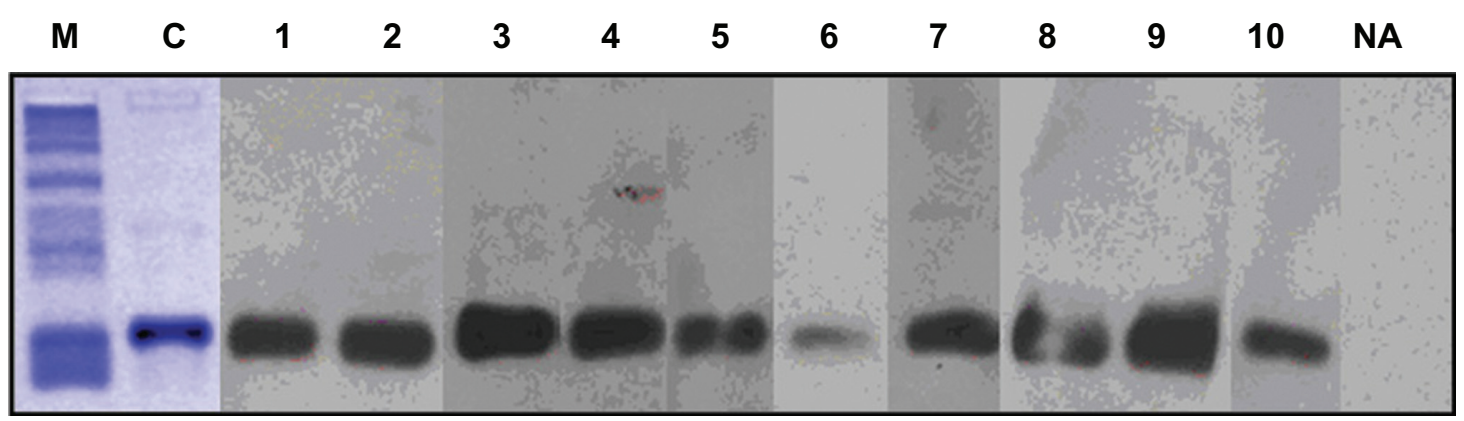

Figure I Western blot analysis of recombinant Par j 2 with ten sera from Parietaria judaica allergic patient (lanes I-10). Lane NA shows incubation with a nonallergenic control serum. Lane C displays a Coomassie Brilliant Blue stained sodium dodecyl sulfate polyacrylamide gel electrophoresis of the purified recombinant Par j 2. Molecular weights are indicated in lane $M$.

recombinant protein was about $0.5 \mathrm{mg} / \mathrm{L}$ of $E$. coli culture (average of three preparations). Protein concentration and purity were estimated on the basis of spectrophotometry analysis $(280 \mathrm{~nm})$, SDS-PAGE, and Coomassie Brilliant Blue staining (Figure 1, lane C). In addition, chromatography of the purified $\mathrm{rPar} \mathrm{j} 2$ on reversed phase HPLC resulted in a well-defined single peak (Figure 2).

As shown in Figure 2, no other component was detected. The IgE-binding activity of the Par $\mathrm{j} 2$ allergen was evaluated by western blot analysis to confirm the allergenic activity of the recombinant protein. Immunoblot experiments performed on ten individual sera from allergic patients revealed that the purified recombinant allergen displayed IgE-binding activity in all tested subjects (Figure 1, lane 1-10). A nonallergic serum was used as negative control showing no unspecific IgE binding (Figure 1, lane NA).

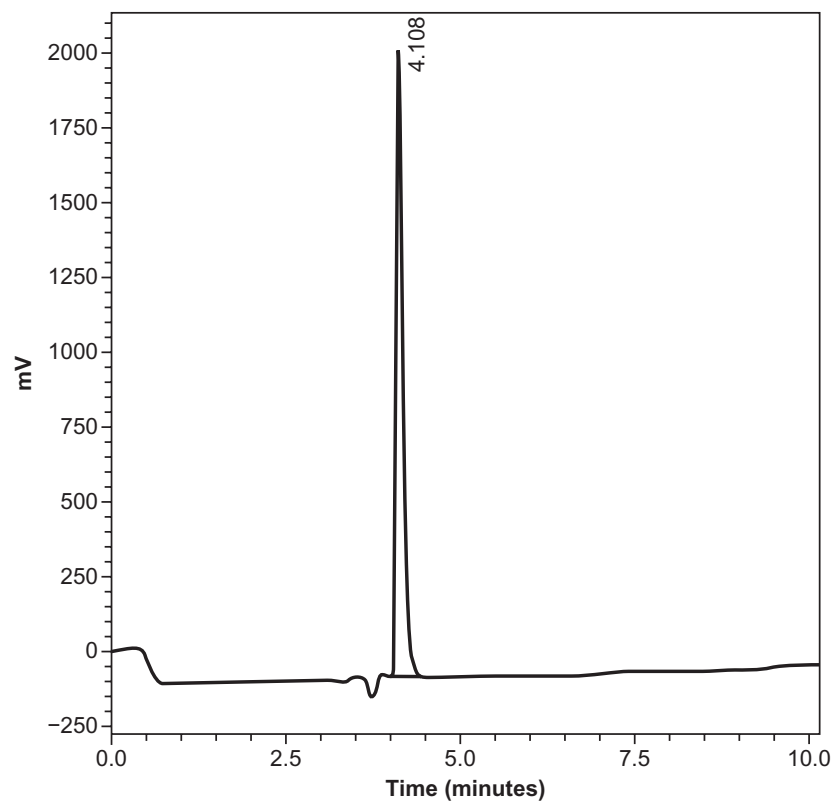

Figure 2 Reversed phase high-performance liquid chromatography elution profile of recombinant Par j 2.
Furthermore, P. judaica extract was coated in enzymelinked immunosorbent assay plates and incubated with sera from four P. judaica allergic patients pretreated with the rPar j 2 allergen (Table 1). This assay showed that the recombinant allergen was capable of inhibiting the majority of human IgE against the whole Parietaria extract raised during the course of natural sensitization. This analysis reinforced the observation that $\mathrm{rPar} \mathrm{j} 2$ resembles the majority of $\mathrm{B}$ cell epitopes against the $P$. judaica pollen and it can be used as a bona fide major Parietaria allergen.

\section{Preparation and characterization of empty and peptide-loaded SLN}

Empty and rPar j 2-loaded SLN were successfully produced by double emulsion (water-in-oil-in-water) solvent evaporation method by using cutin as lipid matrix, and Tween 80 and Epikuron 200 as surfactants. ${ }^{18,19}$ In Figure 3, the schematic representation of this method is reported.

After proper purification, obtained samples were characterized in terms of mean size and zeta potential measurements in bidistilled water. Results are reported in Table 2.

The average diameter of empty SLN was $242.7 \mathrm{~nm}$ and $252.2 \mathrm{~nm}$ for rPar j 2-loaded SLN in bidistilled water. There were slightly lower diameters in the other investigated

Table I Enzyme-linked immunosorbent assay inhibition assay performed on plate-bound Parietaria judaica extract

\begin{tabular}{lll}
\hline $\begin{array}{l}\text { Coated antigen } \\
\text { Inhibitor }\end{array}$ & \multicolumn{2}{c}{ Parietaria judaica extract } \\
\cline { 2 - 3 } & P. judaica extract & Recombinant Par j 2 \\
\hline Patient I & $94 \%$ & $80 \%$ \\
Patient 2 & $98 \%$ & $85 \%$ \\
Patient 3 & $91 \%$ & $65 \%$ \\
Patient 4 & $94 \%$ & $58 \%$ \\
Mean value & $94.25 \%$ & $72 \%$ \\
\hline
\end{tabular}

Note: Numbers indicate the percentage of inhibition. 


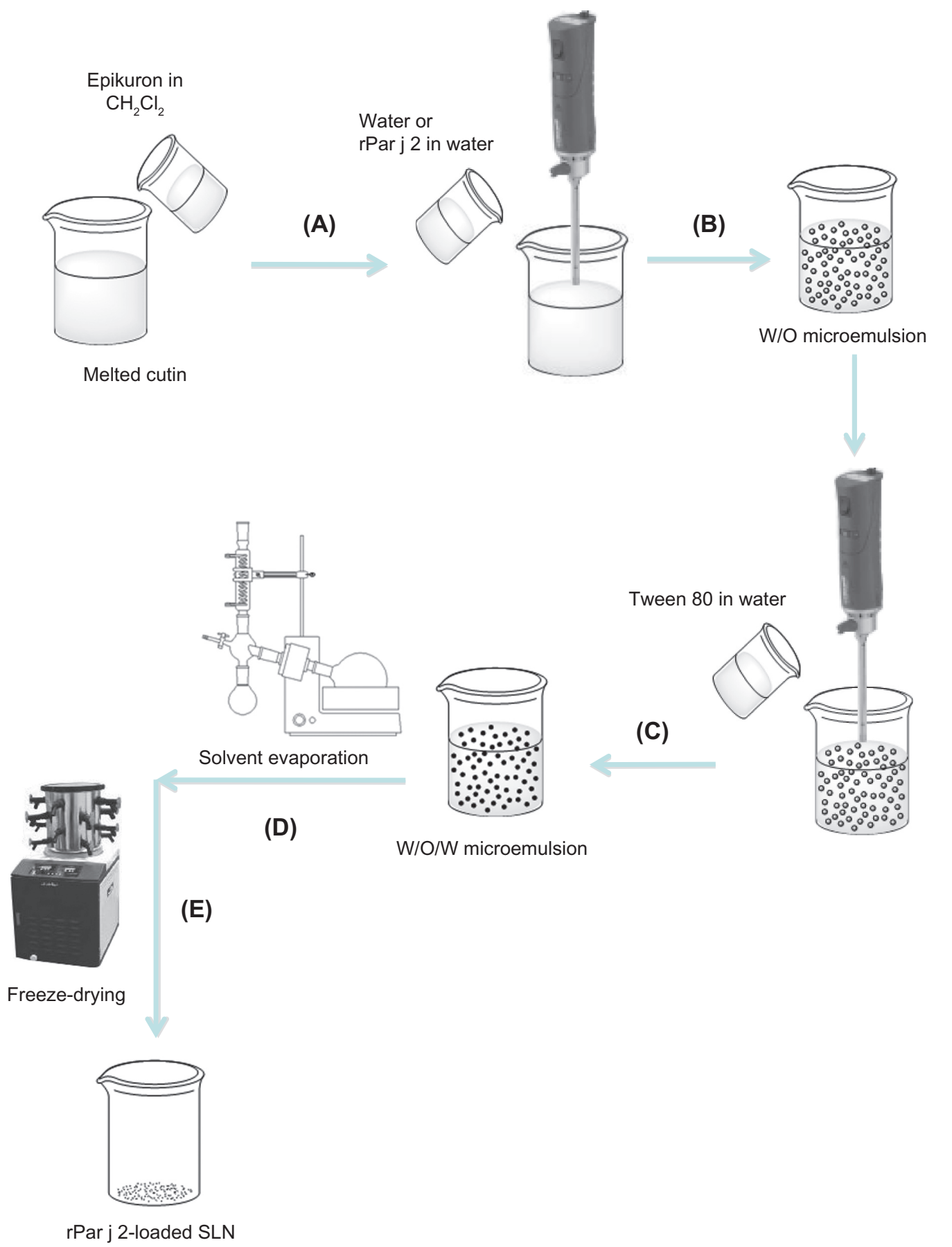

Figure 3 Schematic diagram of solid lipid nanoparticle (SLN) preparation using double emulsion/evaporation method. Lipid heated to $\sim 10^{\circ} \mathrm{C}$ of its melting point and organic solution of dichloromethane $\left(\mathrm{CH}_{2} \mathrm{Cl}_{2}\right)$ containing Epikuron ${ }^{\mathrm{TM}} 200$ added. Aqueous phase or aqueous dispersion of recombinant Par j 2 ( $\mathrm{rPar} \mathrm{j} 2$ ) added under stirring by Ultra-Turrax ${ }^{\circledR}$ TI25 at 13,500 rpm (A), water in oil (w/o) emulsion formed (B), aqueous solution of Tween $80^{\circledR}$ at $2 \%$ and second one at $1 \%$ added under stirring to obtain double emulsion water-in-oil-in-water (w/o/w) (C), organic solvent removed by evaporation (D), and freeze-dried (E).

media; these small differences can be attributed to their different ionic strength of media. The zeta potential values of these structures, also reported in Table 2, were $-44.9 \mathrm{mV}$ for empty SLN and $-38.3 \mathrm{mV}$ for rPar j 2-loaded SLN in bidistilled water, which decreased when they were determined in PBS and sodium chloride $0.9 \%$ weight-in-volume aqueous solution for the potential screening effect of solution ions.

Moreover, an adequate method was developed to determine the encapsulation efficiency of rPar $\mathrm{j} 2$ in cutinbased SLN, which resulted in $40 \%$ weight-in-weight. It was also demonstrated that the protein was mainly 
Table 2 Chemical-physical characterization of empty and recombinant Par j 2-loaded solid lipid nanoparticles

\begin{tabular}{|c|c|c|c|c|c|}
\hline Sample & Dispersing medium & Mean size $(\mathrm{nm})$ & PDI & $\begin{array}{l}\text { Zeta potential } \\
(\mathrm{mV})( \pm \mathrm{SD})\end{array}$ & EE\% (w/w) \\
\hline \multirow[t]{3}{*}{ Empty-SLN } & PBS pH 7.4 & 224.7 & 0.282 & -10.1 & - \\
\hline & $\mathrm{NaCl} 0.9 \%$ & 222.8 & 0.230 & -5.34 & - \\
\hline & $\mathrm{H}_{2} \mathrm{O}$ & 242.7 & 0.270 & $-44.9 \pm 6.99$ & - \\
\hline \multirow[t]{3}{*}{ rPar j 2-loaded SLN } & PBS pH 7.4 & 228.9 & 0.366 & -7.27 & $40.0 \%$ \\
\hline & $\mathrm{NaCl} 0.9 \%$ & 249.0 & 0.286 & -6.74 & $40.0 \%$ \\
\hline & $\mathrm{H}_{2} \mathrm{O}$ & 252.5 & 0.311 & $-38.3 \pm 5.50$ & $40.0 \%$ \\
\hline Empty-SLN (4 months) & $\mathrm{H}_{2} \mathrm{O}$ & 247.3 & 0.287 & $-43.8 \pm 5.88$ & - \\
\hline Empty-SLN (10 months) & $\mathrm{H}_{2} \mathrm{O}$ & 249.7 & 0.295 & $-44.9 \pm 5.76$ & - \\
\hline rPar j 2-loaded SLN (4 months) & $\mathrm{H}_{2} \mathrm{O}$ & 251.5 & 0.383 & $-38.1 \pm 4.18$ & $38.7 \%$ \\
\hline rPar j 2-loaded SLN (I0 months) & $\mathrm{H}_{2} \mathrm{O}$ & 230.5 & 0.364 & $-29.6 \pm 3.26$ & $39.5 \%$ \\
\hline
\end{tabular}

Note: Mean size, polydispersity index, and zeta potential values of empty and recombinant Par j 2-loaded solid lipid nanoparticles in twice-distilled water, phosphate buffered saline at $\mathrm{pH} 7.4$, and sodium chloride $0.9 \%$ weight-in-volume aqueous solution before and after storage.

Abbreviations: EE\%, encapsulation efficiency; $\mathrm{H}_{2} \mathrm{O}$, water; $\mathrm{NaCl}$, sodium chloride; PBS, phosphate buffered saline; PDI, polydispersity index; rPar j 2, recombinant Par j 2; SD, standard deviation; SLN, solid lipid nanoparticles; w/v, weight-in-volume; w/w, weight-in-weight.

entrapped into SLN by an indirect method and it was stable after its incorporation into the SLN, as proven by the lack of degradation peaks in the HPLC chromatogram (data not shown).

The stability of empty and rPar j 2-loaded SLN after storage, for 4 months and 10 months at $4{ }^{\circ} \mathrm{C}$, was evaluated in terms of size, PDI, zeta potential, and drug stability. Results (reported in Table 2) show that both empty and rPar j 2-loaded SLN were stable during storage in tested conditions comparable to that of fresh samples. HPLC analysis also shows that the protein was stable under these storage conditions.
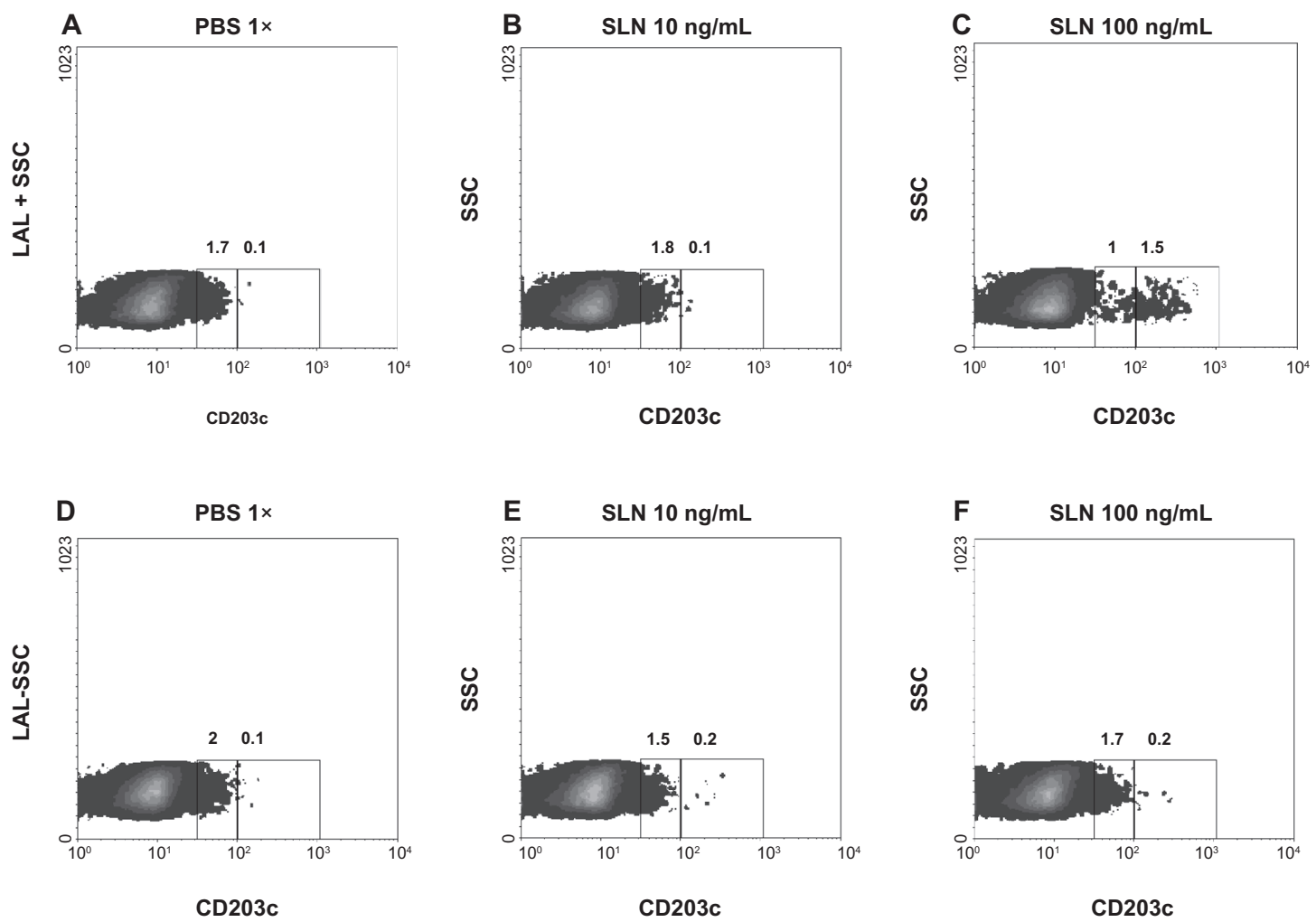

Figure 4 Basophil activation assay. Basophils from one representative healthy subject were stimulated with an increasing concentration of solid lipid nanoparticles produced under standard procedures (panels B and $\mathbf{C}$ ) and with an equimolar concentration of SLN-pyrogen free particles (panels $\mathbf{E}$ and $\mathbf{F}$ ). Panels $\mathbf{A}$ and $\mathbf{D}$ show the unstimulated sample.

Note: Numbers inside the graph express the percentage of cells with upregulated CD203c.

Abbreviations: LAL, limulus amebocyte lysate; PBS, phosphate buffered saline; SLN, solid lipid nanoparticles; SSC, side-scatter characteristics. 
Obtained data (mean size and zeta potential values) support the potential application for sublingual administration of these particles, including after storage, suitable for intravenous circulation. Once into the blood stream, these carriers may be recognized by macrophages as the immune response towards allergens during specific immunotherapy, crucial for the induction of specific $T$ cell tolerance or anergy against allergens and for the generation of allergen-specific blocking IgG subclasses of antibodies. ${ }^{8,20}$

\section{Endotoxin content}

Parenteral pharmaceutical products for animal and human use have to be free from pyrogen contamination. While a pyrogen may in general be defined as any substance causing fever, pyrogens that almost invariably contaminate pharmaceuticals are bacterial endotoxins (LPS) from Gram-negative bacteria. For these reasons, empty SNL and rPar $\mathrm{j} 2$ were analyzed for their endogenous content in LPS. Using standard purification procedures, empty SLN resulted in high LPS contamination (mean $2 \mathrm{EU} / \mu \mathrm{g}$ of particles, average of two evaluations). On the other hand, SNL produced under sterile conditions displayed no LPS contamination. A negative limulus amebocyte lysate test was also observed for the rPar $\mathrm{j} 2$ allergen (average of two evaluations) after purification of the protein on endotoxin removing gel (data not shown).

\section{Basophil activation assay}

At first attempt, the anaphylactic activity of the endotoxinfree SLN was compared to the activity of SLN produced under standard conditions. Their activities were studied by detecting overexpression of the CD203c marker on human basophils. The assay showed that standard preparations of SLN can activate overexpression of the CD203c marker on human basophil (Figure 4, panel C). LPS-free SLN did not show this pattern of activation when tested in the same assay (Figure 4, panels E and F).

The anaphylactic activity of rPar j 2-loaded SLN and allergen obtained in sterile conditions was studied by using
A

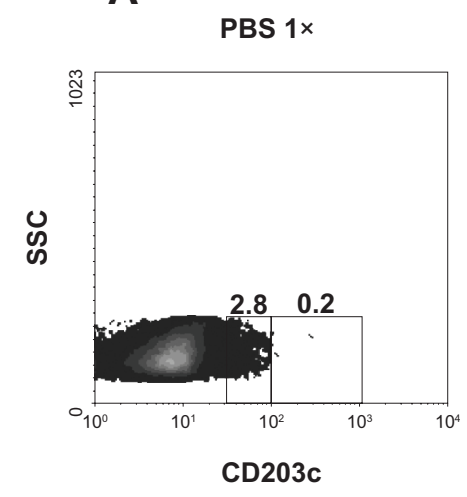

D

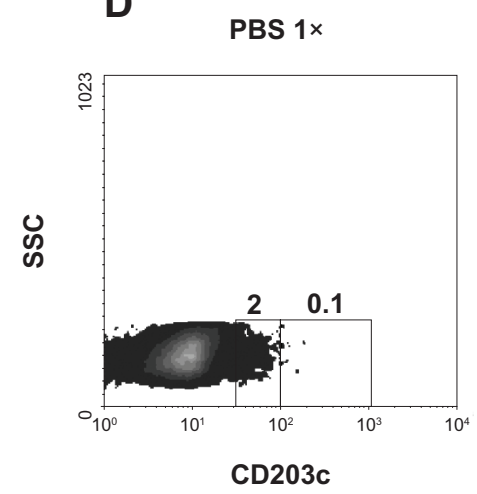

B

SLN + Par j 210 ng/mL

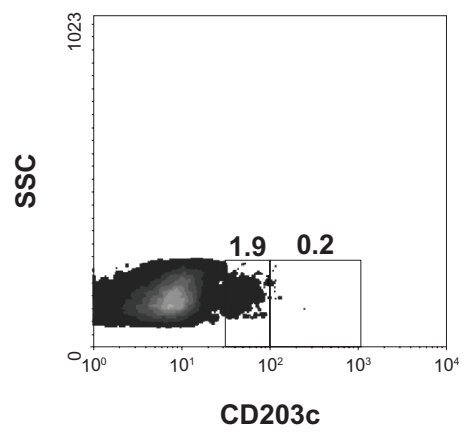

E

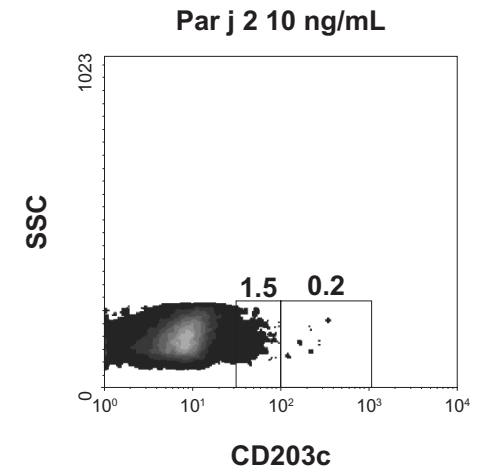

C SLN + Par j $2100 \mathrm{ng} / \mathrm{mL}$

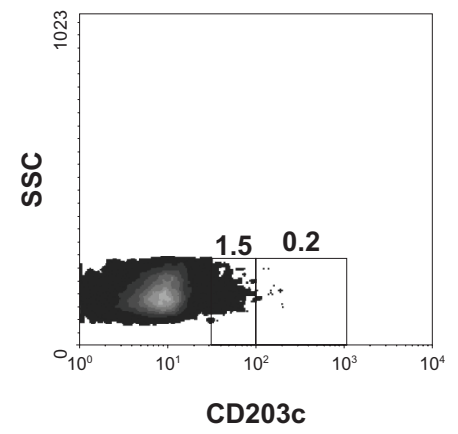

F

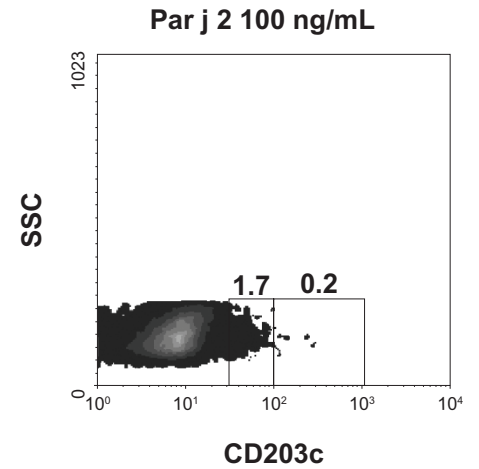

Figure 5 Basophil activation assay. Basophils from one representative Parietaria judaica healthy subject were stimulated with increasing concentration of solid lipid nanoparticles (SLN)-recombinant Par j 2 (panels $\mathbf{B}$ and $\mathbf{C}$ ) and with an equimolar concentration of the recombinant Par j 2 (panels $\mathbf{E}$ and $\mathbf{F}$ ). Panels $\mathbf{A}$ and $\mathbf{D}$ show the unstimulated sample.

Note: Numbers inside the graph express the percentage of cells with upregulated CD203c.

Abbreviations: PBS, phosphate buffered saline; SSC, side-scatter characteristics. 
blood from two healthy subjects. Figure 5 shows a representative plot from one out of two individuals stimulated with increasing concentrations of rPar j 2-loaded SLN (panels B and C) and the free rPar j 2 allergen (panels $\mathrm{E}$ and $\mathrm{F}$ ). Panels $\mathrm{A}$ and $\mathrm{D}$ display the untreated negative controls. This analysis demonstrated that rPar j 2 and rPar j 2-loaded SLN obtained in sterile conditions did not show any anaphylactic activity, which makes them potential candidates for new formulations of stable and safe vaccines.

\section{Conclusion}

This paper has described a new protocol for the preparation of highly purified rPar $\mathrm{j} 2$ allergen and its incorporation into SLN in order to obtain new potential dosage forms of stable and safe vaccines for the treatment of allergic disorders by sublingual route. In fact, extract-based specific immunotherapy currently used in Parietaria allergy vaccination presents several major disadvantages. Generally speaking, extracts are usually poorly characterized mixtures containing nonallergenic and allergenic components with concentration not easily assessable in terms of absolute concentration of allergens and relative quantification of major and minor allergens. ${ }^{21-23}$ In addition, it has been demonstrated that pollen extracts contain proinflammatory substances acting as adjuvants ${ }^{24,25}$ and proteolytic activities which can alter the epithelial integrity contributing to the sensitization and pathogenesis of allergy.

The use of highly purified recombinant allergens can overcome all these problems, allowing standardization of pharmacological treatment. Furthermore, recombinant allergens have been used in clinical trials showing that such products may represent new formulation of tailored immunotherapy vaccines. ${ }^{8}$

Recently, several published papers have reported the characterization of nanoparticles containing allergenic extracts with adjuvant activity ${ }^{26,27}$ and ovalbumin..$^{28,29}$ These studies showed protection from anaphylactic shock and allergenspecific interleukin-10 production from $\mathrm{T}$ cells in animal models suggesting that such formulations may represent sophisticated allergen-delivery systems in allergen specific immunotherapy.

The SLN described in this paper showed average diameters in the colloidal size range, good loading capacity, and highly negative zeta potential. Moreover, they were stable during storage in the used experimental conditions. Furthermore, the anaphylactic activity of rPar j 2-loaded SLN was evaluated demonstrating the safety of the formulation.
In conclusion, this paper has described a novel approach based on the production of Par j 2-loaded SLN carrying the major allergen of the Parietaria pollen produced by DNA recombinant technology. Their chemical-physical and immunological properties were evaluated in vitro, which shows promising characteristics for the set up of immunological studies using animal models.

\section{Acknowledgments}

The authors acknowledge Francesco Mineo for contributing to the language revision of this paper.

\section{Disclosure}

The authors report no conflicts of interest in this work.

\section{References}

1. Holgate ST, Broide D. New targets for allergic rhinitis - a disease of civilization. Nat Rev Drug Discov. 2003;2(11):902-914.

2. Devereux G. The increase in the prevalence of asthma and allergy: food for thought. Nat Rev Immunol. 2006;6(11):869-874.

3. Colombo P, Bonura A, Costa M, et al. The allergens of Parietaria. Int Arch Allergy Immunol. 2003;130(3):173-179.

4. Ayuso R, Carreira J, Polo F. Quantitation of the major allergen of several Parietaria pollens by an anti-Par 1 monoclonal antibody-based ELISA. Analysis of crossreactivity among purified Par j 1, Par o 1 and Par m 1 allergens. Clin Exp Allergy. 1995;25(10):993-999.

5. Scala E, Alessandri C, Bernardi ML, et al. Cross-sectional survey on immunoglobulin E reactivity in 23,077 subjects using an allergenic molecule-based microarray detection system. Clin Exp Allergy. 2010;40(6):911-921.

6. Stumvoll S, Westritschnig K, Lidholm J, et al. Identification of crossreactive and genuine Parietaria judaica pollen allergens. J Allergy Clin Immunol. 2003;111(5):974-979.

7. Bousquet J, Lockey R, Malling HJ. Allergen immunotherapy: therapeutic vaccines for allergic diseases. A WHO position paper. J Allergy Clin Immunol. 1998;102(4 Pt 1):558-562.

8. Valenta R, Ferreira F, Focke-Tejkl M, et al. From allergen genes to allergy vaccines. Annu Rev Immunol. 2010;28:211-241.

9. Compalati E, Rogkakou A, Villa E, Passalacqua G, Canonica GW. Emerging sublingual immunotherapy drugs. Expert Opin Pharmacother. 2010;11(18):2963-2972.

10. Eyles JE, Carpenter ZC, Alpar HO, Williamson ED. Immunological aspects of polymer microsphere vaccine delivery systems. J Drug Target. 2003;11(8-10):509-514.

11. Almeida AJ, Souto EB. Solid lipid nanoparticles as a drug delivery system for peptides and proteins. Adv Drug Deliv Rev. 2007;59(6):478-490.

12. Saraf S, Mishra D, Asthana A, Jain R, Singh S, Jain NK. Lipid microparticles for mucosal immunization against hepatitis B. Vaccine. 2006;24(1):45-56.

13. Pichayakorn W, Kusonwiriyawong C,LakornrachT, Thirapakpoomanunt S, Lipipun V, Ritthidej GC. Solid lipid microparticles for oral Japanese encephalitis vaccine delivery: in vitro study in Caco-2 cells and human intestinal M-cells models and in vivo immunization in mice. Paper presented at: 33rd International Symposium on Controlled Release of Bioactive Materials; July 22-26 2006; Vienna, Austria.

14. Souto EB, Müller RH. Lipid nanoparticles (SLN and NLC) for drug delivery. In: Domb A, Tobata Y, Kumar R, Farber S, editors. Nanoparticles for Pharmaceutical Applications. Valencia, CA: American Scientific Publishers; 2007:103-122. 
15. Müller RH, Radtke M, Wissing SA. Solid lipid nanoparticles and nanostructured lipid carriers. In: Nalwa HS, editor. Encyclopedia of Nanoscience and Nanotechnology. Valencia, CA: American Scientific Publishers; 2004:43-56.

16. Doktorovova S, Gokce E, Ozyazici M, Souto EB. Lipid matrix nanoparticles: pharmacokinetics and biopharmaceutics. Curr Nanosci. 2009;5(3):358-371.

17. Bonura A, Amoroso S, Locorotondo G, et al. Hypoallergenic variants of the Parietaria judaica major allergen Par j 1: a member of the nonspecific lipid transfer protein plant family. Int Arch Allergy Immunol. 2001;126(1):32-40.

18. Garcia-Fuentes M, Torres D, Alonso MJ. New surface-modified lipid nanoparticles as delivery vehicles for salmon calcitonin. Int J Pharm. 2005;296(1-2):122-132.

19. Garcia-Fuentes M, Torres D, Alonso MJ. Design of lipid nanoparticles for the oral delivery of hydrophilic macromolecules. Colloids Surf B Biointerfaces. 2003;27(2-3):159-168.

20. Larche M, Akdis CA, Valenta R. Immunological mechanisms of allergen-specific immunotherapy. Nat Rev Immunol. 2006;6(10): 761-771.

21. Brunetto B, Tinghino R, Braschi MC, Antonicelli L, Pini C, Iacovacci P. Characterization and comparison of commercially available mite extracts for in vivo diagnosis. Allergy. 2010;65(2):184-190.
22. Focke M, Marth K, Flicker S, Valenta R. Heterogeneity of commercial timothy grass pollen extracts. Clin Exp Allergy. 2008;38(8): 1400-1408.

23. Focke M, Marth K, Valenta R. Molecular composition and biological activity of commercial birch pollen allergen extracts. Eur J Clin Invest. 2009;39(5):429-436.

24. Traidl-Hoffmann C, Mariani V, Hochrein H, et al. Pollen-associated phytoprostanes inhibit dendritic cell interleukin-12 production and augment T helper type 2 cell polarization. J Exp Med. 2005;201(4):627-636.

25. Mariani V, Gilles S, Jakob T, et al. Immunomodulatory mediators from pollen enhance the migratory capacity of dendritic cells and license them for Th2 attraction. J Immunol. 2007;178(12):7623-7631.

26. Gomez S, Gamazo C, San Roman B, et al. A novel nanoparticulate adjuvant for immunotherapy with Lolium perenne. J Immunol Methods. 2009;348(1-2):1-8.

27. Broos $\mathrm{S}$, Lundberg $\mathrm{K}$, Akagi $\mathrm{T}$, et al. Immunomodulatory nanoparticles as adjuvants and allergen-delivery system to human dendritic cells: implications for specific immunotherapy. Vaccine. 2010;28(31):5075-5085.

28. Pandey RS, Sahu S, Sudheesh MS, Madan J, Kumar M, Dixit VK. Carbohydrate modified ultrafine ceramic nanoparticles for allergen immunotherapy. Int Immunopharmacol. 2011;11(8):925-931.

29. Gómez S, Gamazo C, San Roman B, et al. Nanoparticles as an adjuvant for oral immunotherapy with allergens. Vaccine. 2007;25(29):5263-5271.
International Journal of Nanomedicine

\section{Publish your work in this journal}

The International Journal of Nanomedicine is an international, peerreviewed journal focusing on the application of nanotechnology in diagnostics, therapeutics, and drug delivery systems throughout the biomedical field. This journal is indexed on PubMed Central, MedLine, CAS, SciSearch ${ }^{\circledR}$, Current Contents ${ }^{\circledR} /$ Clinical Medicine,

\section{Dovepress}

Journal Citation Reports/Science Edition, EMBase, Scopus and the Elsevier Bibliographic databases. The manuscript management system is completely online and includes a very quick and fair peer-review system, which is all easy to use. Visit http://www.dovepress.com/ testimonials.php to read real quotes from published authors. 